\title{
Aminas biogênicas em macroalgas marinhas do Estado do Ceará, Brasil $^{1}$
}

\author{
Biogenic amines in marine macroalgae of the state of Ceará, Brazil
}

\author{
Daniel Barroso de Alencar ${ }^{2}$, Kelma Maria dos Santos Pires-Cavalcante ${ }^{2}$, Márcia Barbosa de Sousa ${ }^{2}$, Francisco \\ Arnaldo Viana $^{3}$ e Silvana Saker-Sampaio ${ }^{4 *}$
}

\begin{abstract}
Resumo - Muitas aminas são comumente encontradas em alimentos de origem vegetal e animal, porém apenas um pequeno número é de interesse por produzirem reações adversas se ingeridas e absorvidas no organismo humano. Dentre elas, a histamina e a tiramina podem desencadear sintomas de intoxicação. As algas marinhas são amplamente consumidas pelos povos orientais, e, no Ocidente, seu consumo encontra-se em expansão. O Brasil não tem esta tradição, mas a diversidade de espécies encontradas no litoral brasileiro as torna potencialmente úteis como alimento humano. Para promovê-las com essa finalidade, são necessários estudos químicos e bioquímicos. No presente trabalho, treze espécies de macroalgas marinhas coletadas na praia do Pacheco, no município de Caucaia - CE, foram preliminarmente analisadas quanto à presença de histamina e tiramina por cromatografia líquida de alta eficiência. A identificação destas aminas biogênicas foi feita com base nos tempos de retenção dos padrões comerciais de dicloridrato de histamina e cloridrato de tiramina, comparados com aqueles correspondentes aos mesmos compostos nos extratos algais. Nenhuma das treze espécies estudadas neste trabalho apresentou histamina e/ou tiramina em quantidades capazes de provocar sintomas de intoxicação através do seu consumo.
\end{abstract}

Palavras-chave - Alga marinha. Histamina. Tiramina. Intoxicação alimentar.

\begin{abstract}
Many amines are commonly found in food of both animal and vegetable origin, however only a small number is of interest since they produce diverse reactions when ingested and absorbed by humans. Among them, histamine and tyramine can cause intoxication symptoms. Marine algae are consumed widely by the eastern civilizations, and in the West, their consumption is expanding. Brazil does not have this tradition, but the diversity of species found throughout the Brazilian coast line make marine algae potentially useful for human ingestion. For such, it is necessary to perform chemical and biochemical studies. In this study, thirteen species of marine macroalgae were collected from Pacheco beach, on the Atlantic coast of Ceará State, Brazil. Preliminarily, they were analysed for histamine and tyramine using high performance liquid chromatography. These amines were identified by comparing the retention time of standard solutions of histamine dihydrochloride and tyramine hydrochloride with those of the alga extracts. Histamine and/or tyramine have not been found in quantities high enough to cause pharmacological actions in any of the thirteen species of marine macroalgae studied.
\end{abstract}

Key words - Marine alga. Histamine. Tyramine. Food poisoning.

\footnotetext{
*Autor para correspondência

${ }^{1}$ Recebido para publicação em 07/10/2009; aprovado em 28/02/2011

Pesquisa Financiada pelo CNPq, Edital Universal 2004

${ }^{2}$ Programa de Pós-Graduação em Engenharia de Pesca, Departamento de Engenharia de Pesca da Universidade Federal do Ceará, Fortaleza-CE, Brasil, daniellpesca@gmail.com, kelmapires@gmail.com,marciabiol@gmail.com

${ }^{3}$ Departamento de Química da Universidade do Estado do Rio Grande do Norte, Campus Universitário Central, Setor III, Rua Prof. Antônio Campos

S/N, Costa e Campos, Mossoró-RN, Brasil, 59.610-090, arnnaldo@yahoo.com.br

${ }^{4}$ Departamento de Engenharia de Pesca da Universidade Federal do Ceará, Campus do Pici, Av. Mister Hull S/N, Bloco 827, Caixa Postal 6.043,

Fortaleza-CE, Brasil, 60.455-970, sakersil@gmail.com
} 


\section{Introdução}

A utilização de algas marinhas para consumo humano está documentada desde 600 a.C., principalmente nos países asiáticos como China, Japão, Coreia e Filipinas, onde as espécies mais consumidas são Laminaria japonica ("kombu"), Undaria pinnatifida ("wakame") e Porphyra spp. ("nori”) (LUNING; PANG, 2003). Os povos orientais possuem o hábito de consumir algas marinhas que são consideradas fontes de vitaminas, fibras dietárias e sais minerais (BURTIN, 2003), revestindo-se em importante fonte de nutrientes. Além dos compostos benéficos presentes nas algas marinhas, há outros considerados indesejáveis como as aminas biogênicas, que são prejudiciais à saúde do homem.

As aminas biogênicas consistem em compostos orgânicos nitrogenados, alcalinos, de baixo peso molecular, formados e degradados por aminação e transaminação de aldeídos ou cetonas, hidrólise de compostos nitrogenados, decomposição térmica ou, principalmente, através da descarboxilação de aminoácidos como resultado do metabolismo normal de animais, vegetais e microorganismos (MAINTZ; NOVAK, 2007).

Estescompostos, quegeralmentepossuematividade biológica, são encontradas em bebidas fermentadas como cervejas (LORET et al., 2005) e vinhos (CHANG et al., 2009; DEL PRETE et al., 2009; PROESTOS et al., 2008); vegetais frescos e fermentados (MORET et al., 2005; MARTÍNEZ-VILLALUENGA et al., 2008); peixes e derivados de pescado (CINQUINA et al., 2004; KIM et al., 2009); produtos cárneos (GENÇCELEP et al., 2008; LATORRE-MORATALLA et al., 2008) e queijos (INNOCENTE et al., 2007; PINTADO et al., 2008). A quantidade presente nos alimentos depende da variedade, maturidade e condições ambientais em que são produzidos. Com relação à concentração original, os níveis podem variar durante o processamento e a estocagem e são influenciados pelas condições de higiene (MAINTZ; NOVAK, 2007).

Após a ingestão de alimentos e/ou bebidas em que há histamina e/ou tiramina, alguns efeitos tóxicos e farmacológicos podem ser desencadeados devido às suas propriedades psicoativas e vasoativas, principalmente em indivíduos com comprometimento no sistema enzimático das monoamina-oxidases (MAO A e MAO B) que ocorre naturalmente no trato gastrintestinal humano. Essas enzimas são inibidas por certos analgésicos e algumas drogas usadas no tratamento de tuberculose, estresse, depressão e mal de Parkinson (BESTER; MOSTERT, 1993; TEN BRINK et al., 1990).

É enorme a utilização de compostos extraídos de algas, principalmente os ficolóides, agar, carragenana e alginato, na manufatura de medicamentos, cosméticos e alimentos, cujo destino é o consumo humano, além do grande número de espécies de algas marinhas que são consumidas in natura ou processadas. As aminas biogênicas não são destruídas pelo calor, ou seja, mesmo que elas ou seus produtos sejam submetidos a tratamento térmico, as aminas uma vez formadas permanecerão ativas. A determinação de aminas biogênicas (histamina, tiramina, agmatina, putrescina, cadaverina, espermina e espermidina) em alimentos e bebidas está relacionada com o potencial tóxico (LARQUÉ et al., 2007). Estudos capazes de revelar a presença de aminas biogênicas em algas marinhas são muito escassos, existindo pouca informação na literatura sobre sua ocorrência, embora seu potencial como alimento humano seja crescente (PIRES et al., 2008; SOUSA et al., 2008).

O objetivo do presente trabalho foi verificar preliminarmente a ocorrência de histamina e tiramina em treze espécies de macroalgas comumente encontradas no litoral cearense e determinar sua concentração.

\section{Material e métodos}

Treze espécies de macroalgas marinhas (Chlorophyta: Caulerpa cupressoides, C. mexicana, C. racemosa, C. prolifera, C. sertularioides e Ulva fasciata; Rhodophyta: Botryocladia occidentalis, Bryothamnion seaforthii, B. triquetrum e Cryptonemia crenulata; e Phaeophyta: Dictyota dichotoma, Dictyopteris delicatula e Lobophora variegata) foram coletadas durante a maré baixa na Praia do Pacheco, Caucaia-Ceará, em agosto de 2007 e levadas para o laboratório. O material coletado foi lavado para remoção de impurezas e epífitas macroscópicas e colocado sobre papel absorvente para drenar o excesso de água. Porções de aproximadamente $100 \mathrm{~g}$ de cada espécie foram desidratadas em estufa a $40{ }^{\circ} \mathrm{C}$ por $15 \mathrm{~h} . \mathrm{O}$ material seco foi triturado, até a obtenção de um pó fino, e usado para a preparação dos extratos em $\mathrm{HCl} 0,1 \mathrm{M}$, na proporção $1: 10(\mathrm{p} / \mathrm{V})$, em triplicata.

A extração bruta foi procedida em banho-maria a $95{ }^{\circ} \mathrm{C}$ por 15 min. Em seguida, uma extração seletiva foi realizada em $n$-butanol, após alcalinização com solução de $\mathrm{NaOH} 5 \mathrm{M}$ saturada com $\mathrm{NaCl}$ e de volta para $\mathrm{HCl} 0,1 \mathrm{M}$. O excesso de $n$-butanol foi completamente evaporado.

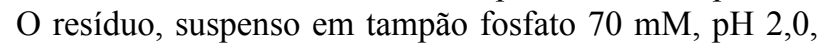
foi filtrado em membrana de $0,45 \mu \mathrm{m}$. Alíquotas de $100 \mu \mathrm{L}$ foram injetadas manualmente em um sistema cromatográfico constituído de uma coluna Atlantis dC18 $(4,6 \times 250 \mathrm{~mm})$, como fase estacionária, e como fase móvel uma solução de fosfato de potássio monobásico 70 $\mathrm{mM}$, cujo $\mathrm{pH}$ foi ajustado para 2,0 com ácido fosfórico $85 \%$, contendo $7 \mathrm{mM}$ de ácido pentassulfônico (solvente A) e acetonitrila (solvente B). No programa de eluição de gradiente, 
a mistura de solventes foi bombeada a $1 \mathrm{~mL} \mathrm{~min}^{-1}$ por uma bomba AKTAbasic 10, modelo P-900, (GEhealthcare), da seguinte maneira: de 0 a $7 \mathrm{~min}, 96,8 \%$ de $\mathrm{A}$ e $3,2 \%$ de B; e de 7 a $15 \mathrm{~min}, 88 \%$ de A e $12 \%$ de B. No final da corrida, a coluna foi re-equilibrada por 6 min com as condições iniciais da análise. O monitor AKTAbasic UV 900 (GEhealthcare) foi ajustado em $271 \mathrm{~nm}$ e $216 \mathrm{~nm}$ para a leitura de histamina e tiramina, respectivamente. Os cromatogramas foram registrados através do sistema de controle Unicorn ${ }^{\mathrm{TM}}$, versão 5.0.

A identificação de histamina e tiramina nos extratos algais foi feita por comparação com os tempos de retenção obtidos para as soluções padrão preparadas com padrões comerciais da Sigma-Aldrich, dicloridrato de histamina (H7250) e cloridrato de tiramina (T-2879), respectivamente. As curvas de calibração foram feitas para estabelecer a existência de correlação de Pearson $(p \leq 0,05)$ entre as quantidades injetadas na coluna e as áreas dos picos correspondentes às diferentes concentrações. Os extratos algais e os padrões foram tratados de forma idêntica, considerando volume de reagentes e alíquotas transferidas entre etapas do procedimento.

As concentrações de histamina e tiramina, expressas em $\mathrm{mg} \mathrm{kg}^{-1}$ de peso seco, nos extratos das algas analisadas foram calculadas pela fórmula abaixo:

$$
\mathrm{mg} \mathrm{kg}^{-1}=\frac{\text { área amostra }}{\text { área padrão }} \times \mu \mathrm{g} \text { padrão } \times \frac{1.000}{\text { peso alga }(\mathrm{g})} \times \frac{1}{1.000}
$$

\section{Resultados e discussão}

A existência de correlação de Pearson entre as áreas dos picos e as quantidades $(0,005 ; 0,01 ; 0,02 ; 0,03 ; 0,04$ e $0,05 \mu \mathrm{g}$ ) aplicadas separadamente na coluna permitiu a quantificação de histamina $(\mathrm{r}=0,9996 ; p<0,0001) \mathrm{e}$ de tiramina $(\mathrm{r}=0,9982 ; p<0,0001)$ nos extratos algais. Os compostos que apresentaram tempos de retenção semelhantes aos dos padrões comerciais, dicloridrato de histamina $(4,64 \pm 0,04 \mathrm{~min}, \mathrm{n}=15)$ e cloridrato de tiramina $(14,38 \pm 0,06 \min , \mathrm{n}=15)$, foram co-cromatografados e considerados histamina e tiramina, respectivamente.

Normalmente, a identificação de compostos separados por cromatografia líquida de alta eficiência (CLAE) é feita com base no tempo de retenção e na cocromatografia. Para que este procedimento seja aceito, é recomendável que não haja variações muito grandes entre o tempo de retenção referente ao composto padrão e aquele da amostra. Cinquina et al. (2004), por exemplo, aceitaram uma variação de $\pm 2,5 \%$ entre o tempo de retenção da amina presente na amostra e o tempo de retenção do padrão correspondente. Este percentual foi muito superior ao observado neste trabalho tanto para histamina quanto para tiramina.

Alíquotas de $100 \mu \mathrm{L}$ dos padrões comerciais (dicloridrato de histamina e cloridrato de tiramina) com concentração de $1 \mathrm{mg} \mathrm{mL} \mathrm{mL}^{-1}$ foram injetadas no sistema cromatográfico em dias consecutivos $(\mathrm{n}=15)$, revelando tempos de retenção com desvios-padrão relativos iguais a 0,86 e $0,45 \%$, respectivamente. A histamina padrão cocromatografada com $1 \mathrm{~g}$ de alga apresentou recuperação variando de $35,1 \%$ a $80,7 \%$, com média igual a $54,3 \%$, quando comparada com o padrão cromatografado na ausência da alga. Para a tiramina, esse intervalo de variação foi de $53,1 \%$ a $90,6 \%$, com média igual a $73,3 \%$.

A presença de histamina foi observada em onze $(85 \%)$ das treze espécies analisadas neste trabalho, não tendo sido detectada nos extratos de Caulerpa racemosa e Dictyota dichotoma. A tiramina, por sua vez, foi encontrada em oito (62\%) das treze espécies estudadas, não tendo sido evidenciada sua presença nos extratos de Caulerpa prolifera, C. cupressoides, Ulva fasciata, Lobophora variegata e Cryptonemia crenulata (TAB. 1). É importante ressaltar que, nos extratos em que estas aminas foram detectadas, suas quantidades não ultrapassaram $0,01 \mathrm{mg} \mathrm{kg}^{-1}$ de alga desidratada.

Os limites máximos de histamina e tiramina permitidos em alimentos são claros na legislação de muitos países, não havendo, no entanto, valores estabelecidos especificamente para algas marinhas, nem mesmo naqueles países onde elas são tradicionalmente consumidas como alimento. No Brasil, o Ministério da Agricultura, através da Portaria № 185, de 13 de maio de 1997 (BRASIL, 1997), estabelece o limite de 100 ppm (100 mg por kg de músculo) de histamina no músculo de peixes das espécies pertencentes às famílias Scombridae, Scomberesocidae, Clupeidae, Coryphaenidae e Pomatomidae. Da mesma forma que nos demais países, nenhuma referência é feita às algas marinhas.

A verdade é que embora a histamina ocorra em uma ampla variedade de plantas superiores, sua presença em algas marinhas tem sido relatada em um número limitado de espécies. Barwell (1979) examinou a presença de histamina em 77 espécies de algas marinhas do Reino Unido. Dentre todos os membros das Chlorophyta, Rhodophyta e Phaeophyta, ela foi detectada apenas na alga marinha vermelha, Furcellaria lumbricalis, e seu teor variou de 245 a $1.780 \mu \mathrm{g} \mathrm{g}^{-1}$ de peso seco. Para o autor, a presença de histamina nas amostras de $F$. lumbricalis coletadas em três locais diferentes e distantes um do outro parece ser uma característica consistente dessa espécie. A ausência de histamina nas demais algas estudadas foi atribuída ao fato de que poucas espécies foram analisadas mais de uma vez, sendo perfeitamente possível encontrá-la em algum estágio do ciclo de vida da espécie. 
Tabela 1 - Ocorrência de histamina e tiramina nos extratos de algas marinhas pertencentes às divisões Chlorophyta, Rhodophyta e Phaeophyta, coletadas na praia do Pacheco, Caucaia, Ceará, em agosto de 2007

\begin{tabular}{lcc}
\hline \multicolumn{1}{c}{ Espécies de algas } & Histamina & Tiramina \\
\hline Chlorophyta & + & - \\
Caulerpa cupressoides & + & + \\
Caulerpa mexicana & + & - \\
Caulerpa prolifera & - & + \\
Caulerpa racemosa & + & + \\
Caulerpa sertularioides & + & - \\
Ulva fasciata & & \\
Rhodophyta & + & + \\
Botryocladia occidentalis & + & + \\
Bryothamnion seaforthii & + & + \\
Bryothamnion triquetrum & + & - \\
Cryptonemia crenulata & & \\
Phaeophyta & - & + \\
Dictyota dichotoma & + & - \\
Dictyopteris delicatula & + & + \\
Lobophora variegata & & \\
\hline
\end{tabular}

+ Presença de aminas biogênicas; - Ausência de aminas biogênicas

Posteriormente, partes distintas do talo da $F$. lumbricalis, em diferentes estágios de desenvolvimento (gametófitas e tetraesporófitas), foram analisadas. Uma quantidade relativamente alta de histamina (60 a $500 \mu \mathrm{g} \mathrm{g}^{-1}$ de peso fresco) foi encontrada e associada a uma provável proteção natural contra organismos herbívoros, para que o espécime garanta sua sobrevivência até atingir a maturidade (BARWELL, 1989; BARWELL, 1994), que está estimada de 4 a 6 anos.

Mourão et al. (2007) analisaram 15 espécies de algas marinhas verdes, vermelhas e pardas, coletadas no litoral cearense em julho de 2004, quanto à presença de histamina. Em apenas duas espécies de rodófitas, Botryocladia occidentalis e Cryptonemia crenulata, eles encontraram um composto que foi preliminarmente considerado como histamina.

Semelhantemente ao observado para a histamina, ainda são muito poucos os estudos sobre a ocorrência de tiramina em algas marinhas. Os raros registros na literatura relatam sua presença na microalga verde Scenedesmus acutus (ROLLE et al., 1977), nas macroalgas vermelhas, Chondrus crispus e Polysiphonia urceolata e parda, Laminaria saccharina (STEINER; HARTMANN, 1968; HARTMANN; AUFERMAN, 1973; KNEIFEL etal., 1977). Saker-Sampaio (1997) investigou a presença de tiramina na feofícea Laminaria digitata, não tendo encontrado nenhum componente similar a ela nesta espécie. $\mathrm{Na}$ rodofícea Palmaria palmata, ela foi encontrada em quantidades variáveis $\left(<1,0\right.$ a $85,0 \mu \mathrm{g} \mathrm{g}^{-1}$ de peso fresco) ao longo do ano.

As algas marinhas representam um grande potencial para a nutrição humana, pois apresentam baixos valor calórico e teor de lipídios e alto valor protéico, sendo excelentes fontes de vitaminas, minerais e fibras dietárias. Desta forma, a presença de aminas farmacologicamente ativas em algas ou produtos de algas marinhas deve ser efetivamente estudada em um maior número de espécies. Dependendo da quantidade presente, elas podem representar um risco à saúde do consumidor por desencadear sintomas de intoxicação que podem inclusive levar à morte.

\section{Conclusão}

Em todas as 13 espécies de algas marinhas estudadas foi observada a ocorrência de histamina e/ ou tiramina. Entretanto, em nenhuma das espécies com presença de histamina e/ou tiramina foi evidenciada quantidades capazes de provocar sintomas de intoxicação através do seu consumo. 


\section{Agradecimentos}

Ao Conselho Nacional de Desenvolvimento Científico eTecnológico(CNPq), porconcessãodebolsaeapoiofinanceiro para a realização desta pesquisa; à Fundação Cearense de Apoio ao Desenvolvimento Científico e Tecnológico (FUNCAP) e à Coordenação de Aperfeiçoamento de Pessoal de Nível Superior (CAPES), por concessão de bolsas.

\section{Referências}

BARWELL, C. J. The occurrence of histamine in the red alga Furcellaria lumbricalis (Huds.) Lamour. Botanica Marina, v. 22, n. 06, p.399-401, 1979.

BARWELL, C. J. Distribution of histamine in the thallus of Furcellaria lumbricalis. Journal of Applied Phycology, v. 01, p. 341-344, 1989.

BARWELL, C. J. Pharmacologically-active amines in some marine algae and algal food products. Journal of Home \& Consumer Horticulture, v. 01, n. 01, p. 77-82, 1994.

BESTER, B. H.; MOSTERT, J. F. Biogenic amines in food. The South African Journal of Food Science and Nutrition, v. 05, n. 04, p. 103-111, 1993.

BRASIL. Portaria № 185 de 13 de maio de 1997. Regulamento técnico de identidade e qualidade de peixe fresco (inteiro e eviscerado); considerando a necessidade de padronizar os processos de elaboração dos produtos de origem animal. Ministério da Agricultura. Brasília, DF. MA, 1997. Disponível em: <http://extranet.agricultura.gov.br/ sislegis-consulta>. Acesso em: 18 nov. 2010.

BURTIN, P. Nutritional value of seaweeds. Electronic Journal of Environmental, Agricultural and Food Chemistry, v. 02, n. 04, p. 498-503, 2003. Disponível em: $<$ http://ejeafche.uvigo.es/index. php?option $=$ com_docman\&task $=$ cat_view\&gid=70\&Itemid=33> Acesso em: 18 nov. 2010.

CHANG, S. C. et al. Histamine production by bacilli bacteria, acetic bacteria and yeast isolated from fruits wines. LWT - Food Science and Technology, v. 42, n. 01, p. 280-285, 2009.

CINQUINA, A. L. et al. Validation and comparison of analytical methods for the determination of histamine in tuna fish samples. Journal of Chromatography A, v. 1032, n. 1-2, p. 79-85, 2004.

DEL PRETE, V. et al. Occurrence of biogenic amines in wine: The role of grapes. Food Chemistry, v. 112, n. 02, p. 474-481, 2009.

GENÇCELEP, H. et al. Determination of biogenic amines in sucuk. Food Control, v. 19, n. 09, p. 868-872, 2008.

HARTMANN, T.; AUFERMAN, B. Physiology of amine formation in marine red alga Polysiphonia urceolata. Marine Biology, v. 21, n. 01, p. 70-74, 1973.

INNOCENTE, M. et al. Determination of biogenic amines in cheese using HPLC technique and direct derivatization of acid extract. Food Chemistry, v. 101, n. 03, p. 1285-1289, 2007.

KIM, M. K. et al. Biogenic amine formation and bacterial contribution in fish, squid and shellfish. Food Chemistry, v. 116, n. 01, p. $87-95,2009$
KNEIFEL, H. et al. Analysis of amines in algae by highperformance liquid chromatography. Journal of Phycology, v. 13, p. 36-36, 1977. Suplemento.

LARQUÉ, E. et al. Biological significance of dietary polyamines. Nutrition, v. 23, n. 01, p. 87-95, 2007.

LATORRE-MORATALLA, M. L. et al. Biogenic amines in traditional fermented sausages produced in selected European countries. Food Chemistry, v. 107, n. 02, p. 912-921, 2008.

LORET, S. et al. Levels of biogenic amines as a measure of the quality of the beer fermentation process: Data from Belgian samples. Food Chemistry, v. 89, n. 04, p. 519-525, 2005.

LUNING, K.; PANG, S. J. Mass cultivation of seaweeds: current aspects and approaches. Journal of Applied Phycology, v. 15, n. 2-3, p. 115-119, 2003.

MAINTZ, L.; NOVAK, N. Histamine and histamine intolerance. American Journal of Clinical Nutrition, v. 85, n. 05 , p. 1185-1196, 2007.

MARTÍNEZ-VILLALUENGA, C. et al. Food safety evaluation of broccoli and radish sprouts. Food and Chemical Toxicology, v. 46, n. 05, p. 1635-1644, 2008.

MORET, S. et al. A survey on free biogenic amine content of fresh and preserved vegetables. Food Chemistry, v. 89, n. 03, p. 355-361, 2005.

MOURÃO, J. O. B. et al. Estudo preliminar sobre a ocorrência de histamina em macroalgas marinhas do Estado do Ceará. Revista Ciência Agronômica, v. 38, n. 01, p. 64-68, 2007.

PINTADO, A. I. E. et al. Microbiological, biochemical and biogenic amine profiles of Terrincho cheese manufactured in several dairy farms. International Dairy Journal, v. 18, n. 06, p. 631-640, 2008.

PIRES, K. M. S. et al. Teores de alfa-caroteno e beta-caroteno em macroalgas marinhas desidratadas. Revista Ciência Agronômica, v. 39, p. 257-262, 2008.

PROESTOS, C. et al. Determination of biogenic amines in wines by HPLC with precolumn dansylation and fluorimetric detection. Food Chemistry, v. 106, n. 03, p. 1218-1224, 2008.

ROLLE, I. et al. Amines in unicellular green algae. 2. Amines in Scenedesmus acutus. Analytical Biochemistry, v. 77, $\mathrm{n}$. 01, p. 103-109, 1977.

SAKER-SAMPAIO, S. Evaluation of Palmaria palmata and Laminaria digitata as potential human food products. 1997. $165 \mathrm{f}$. Thesis $(\mathrm{PhD})$ - University of Portsmouth, Portsmouth.

SOUSA, M. B. et al. $\alpha$-, $\beta$-caroteno e $\alpha$-tocoferol em algas marinhas in natura. Ciência e Tecnologia de Alimentos, v. 28, n. 04, p. 953-958, 2008.

STEINER, M.; HARTMANN, T. The occurrence and distribution of volatile amines in marine algae. Planta, v. 79, n. 02, p. 113-121, 1968.

TEN BRINK, B. T. et al. Occurrence and formation of biologically active amines in foods. International Journal of Food Microbiology, v. 11, n. 01, p. 73-84, 1990. 